\title{
GIARDIA INTESTINALIS ASSEMBLAGES AMONG EGYPTIAN SYMPTOMATIC CHILDREN: PREVALENCE AND SEASONAL DISTRIBUTION IN CAIRO, EGYPT
}

\author{
By \\ SAMIR A.TAHA ${ }^{1^{*}}$, ZEIN ABD AL AAL ${ }^{1}$, NESREEN S. SALEH ${ }^{2}$ \\ AND AYMAN A. EL-BADRY ${ }^{3}$ \\ Department of Zoology, Faculty of Science, Zagazig University ${ }^{1}$
}

Department of Zoology, Faculty of Science, Benghazi University, Libya ${ }^{2}$ and Department of Medical Parasitology, Faculty of Medicine, Cairo University, Cairo, Egypt $^{3}\left({ }^{*}\right.$ Correspondence: sameertaha@hotmail.com Mob.++01003811559)

\begin{abstract}
Giardia intestinalis is one the commonest enteric intestinal protozoan pathogens worldwide, notorious for its seasonal prevalence and wide age span of population infected G. intestinalis causes diarrhea in humans, especially in children. The present study aimed to evaluate the prevalence and genetic diversity of $G$. intestinalis isolated from Egyptian symptomatic children. A total of 176 faecal samples of children, from Aboul-Reesh Pediatrics Hospital, Cairo. Direct wet mount and formalin-ether sedimentation techniques were applied for microscopic determination of Giardia infection in faecal samples. DNA was extracted from positive stool samples and amplified by nested polymerase chain reaction (nPCR) using specific primers of $G$. intestinalis Trios Phosphate Isomerase (TPI) gene. Assemblages were determined using sequence analysis of the TPI gene .Out of the 176 samples, G. intestinalis was detected in $33(18.75 \%)$ and 24 $(13.63 \%)$ cases using Coproscopy and nPCR, respectively. There was a significant predominance of assemblage B (20 cases [83.33\%]) versus assemblage A (4 cases [16.66\%]) In this study, molecular analysis revealed that assemblages A and B are the most common types with a predominance of assemblage B. These findings suggest that anthroponotic transmission could be a dominant transmission route for giardiasis in Egypt.
\end{abstract}

Keywords: Children, TPI gene, Giardia intestinalis, PCR- sequence.

\section{Introduction}

Giardia intestinalis (syn. G. duodenalis, G. lamblia) is one of the commonest worldwide intestinal parasites reached up 30\% among Eastern Mediterranean and African children (WHO, 2015). Giardiasis is notorious for its seasonal prevalence and wide age span of population infected (Savioli et al, 2006). G. intestinalis is the only zoonotic species infects man and animals (Fahmy et $a l, 2015)$. Its prevalence in Egypt was up to $27.3 \%$ among symptomatic children with chronic diarrhea (Bayoumy et al, 2010) and considered the most important non-viral infectious agent of human diarrhea in humans. In developing countries it caused about 2.5 million cases of childhood diarrhea annually (Younas et al, 2008).

Transmission occurs by faecal-oral route with food, and water or recreational water contaminated with cysts in feces, with some waterborne outbreaks from water contaminated with faeces (Adam et al, 2016).

The severity of infectious enteric diseases, including giardiasis, is seasonal in distribution and prevalence (Lai et al, 2012). The main drivers of enteric disease seasonality are socio-demographic and behavioral factors as well as environmental factors; these factors affect giardiasis transmission (Ismail et al, 2016).

Clinical symptoms of giardiasis varied from asymptomatic infection to acute or chronic diarrhea with abdominal cramps, nausea, vomiting, bloating and malabsorption, which can lead to failure to thrive and retarded growth, as well as, allergic response to Giardia parasite or its products (Robertson et al, 2010; Hussein et al, 2017).

An epidemiological molecular determined genetic diversity of $G$. intestinalis, considered its seasonality, children ages, associated symptoms, and risk factors among Egyptian diarrheic children (Ismail et al, 2016). 
Most targeted genes for molecular studies of G. intestinalis depended upon the analysis of small sub-unit ribosomal RNA (ssurRNA), glutamate dehydrogenase (gdh), triose phosphate isomerise (TPI), elongation factor 1-alpha (ef-1 $\alpha$ ), GLORF-C4 genes, and $\beta$-giardin (bg) (Heyworth 2016).

Nucleotide sequencing of TPI determined the different genotypes of $G$. intestinalis, confirming the high genetic heterogeneity displayed by Giardia spp. at this locus. TPI sequences proved that some isolates $G$. intestinalis from animals are of zoonotic potential. Also, the TPI was useful in the taxonomy, differentiation, and detection of $\mathrm{Gi}^{-}$ ardia spp. (Sulaiman et al, 2003).

$G$. intestinalis complex is found in the intestine of a wide variety of vertebrate hosts. This complex is morphologically similar, but with genetically different assemblages (Cacciò and Ryan 2008). Some assemblages of $G$. intestinalis infect a wide range of mammal hosts, whereas others appear to be restricted to groups such as cats or dogs, and some are known to infect only one host species. The assemblages include A to H. Assemblages A \& B isolates infect the broadest panel of hosts, including humans, and various other mammals. C and D infect dogs and cats, while E infects cattle, sheep, and goats. Furthermore, $F$ infects only cats, $G$ infects rats, and $\mathrm{H}$ infects seals (Lasek-Nesselquist et al, 2010; Feng and Xiao 2011).

Giardiasis is one of the most important public health problems due to its high prevalence and major impact on the patients' quality of life. G. intestinalis causes diarrhea in humans, especially in children.

The present copro-molecular study aimed to evaluate the prevalence and genetic diversity of G. intestinalis isolated from Egyptian children

\section{Materials and Methods}

Fecal samples were collected from 176 children of both sexes with ages ranged from 1 to 12 years, Aboul-Reesh Hospital, Cairo from the period of August 2016 to July 2017 throughout the different seasons of the year.
This study has been approved by the ethical committee of Aboul-Reesh Pediatric Hospital and performed in accordance with the ethical standards as laid down in the 1964 Declaration of Helsinki and its later amendments or comparable ethical standards. Families of all children were informed verbally about the purpose of the study, and the collection of samples was performed after obtaining consents. Participation in the study was optional.

Microscopic examination: All fecal samples were collected from every child; a specimen part was preserved in formalin saline and examined directly as wet mount before and after concentration. Samples were then stored at $-20^{\circ} \mathrm{C}$, without preservative, for PCR analyses (Lab. of Molecular Medical Parasitology (LMMP), Faculty of Medicine, Cairo University, Egypt).

PCR: DNA extraction was performed with the favor stool DNA spin columns isolation mini Kit (Favorgen Biotech Corporation ping-Tung 908, Taiwan, Cat. No. FASTI001) with a modification of prolongation of incubation to $95^{\circ} \mathrm{C}$ for $1 \mathrm{hr}$ after thermal shock (cycling of deep freezing in liquid nitrogen for $5 \mathrm{~min}$ and immediately transferred into a $95^{\circ} \mathrm{C}$ water bath for $5 \mathrm{~min}$, repeated for 5 cycles). Purified DNA was measured for concentration and purity.

nPCR of TPI gene: Nested PCR was done by analysis of the TPI gene included two consecutive PCR reactions. The first reaction amplified the $605 \mathrm{bp}$ fragment by using an external pair of primer, and the second reaction amplified the 530 bp fragment, using two sets of oligonuclutide primers (Tab. 1). The reaction mixture consisted of $12.5 \mu \mathrm{l}$ PCR Master Mix, $1 \mu$ l of each primer, $2.5 \mu 1$ of template DNA for the primary reaction and $1 \mu \mathrm{l}$ for the secondary reaction, $0.1 \mu \mathrm{l}$ Taq polymerase (as an activator), and $7.9 \mu \mathrm{l}$ of sterile distilled water to complete a total volume of $25 \mu 1$. Cycling conditions were done (Sulaiman et al, 2003). Reactions were performed in a gradient thermal cycler after adjusting the thermal profile to initial dena- 
turation at $95^{\circ} \mathrm{C}$ for $4 \mathrm{~min}$, followed by 35 cycles of amplification consisting of denaturation at $94^{\circ} \mathrm{C}$ for 60 second, annealing at $65^{\circ} \mathrm{C}$ for 60 second, and extension at $72^{\circ} \mathrm{C}$ for 60 second. Final elongation was performed at $72^{\circ} \mathrm{C}$ for $10 \mathrm{~min}$. The secondround PCR was identical to the first-round PCR except for denaturation at $94^{\circ} \mathrm{C}$ for 50second, annealing at $54^{\circ} \mathrm{C}$ for 35 second, and extension at $72^{\circ} \mathrm{C}$ for 50 second. Amplified PCR products were separated by electrophoresis on $2 \%$ agarose gel in TBE buffer and visualized under a trans-illuminator after staining with ethidium bromide.

Sequence analysis of TPI gene: Genotyping was performed using sequence analysis of the nPCR products of $G$. intestinalis. The secondary PCR products were sequenced using AL3544 primer. Nucleotide sequences were edited manually and the sequence representatives for each of the assemblages were identified. The resulted sequences were analyzed and compared with similar $G$. intestinalis sequences deposited in the GenBank at NCBI database.

Statistical analysis: Aassessed potential association between the infection with Giardia and various studied risk factors (age, sex and seasonality), by a chi-square test of association for infected samples and the estimated risk factors. Significance of association was: $\mathrm{P}>0.05$ : non-significant, $\mathrm{P}<0.05$ : significant. Analyses were conducted using Graph Pad Prism V.5 software (Graph Pad Software, Inc., San Diego, California).

\section{Results}

This cross-sectional study was conducted with 176 samples of children to detect of $G$. intestinalis by using microscopy and molecular differentiation of the parasite genotypes.

By microscopy 33/143 samples (18.75\%) were positive and $81.25 \%$ negative (Tab. 2). The prevalence of $G$. intestinalis was detected in both sex, but the infection in males exceeded that of females. G. intestinalis was detected in samples during summer, spring and autumn, but none in winter. All examined age groups, with infants (less than 2 years) showed the lowest prevalence (Tab. 3 ), But, without association between the assemblages of giardiasis and any risk factors as age, sex or infection seasonality (Tab. 4).

The PCR products produced targeting TPI were sequenced. Blast analyses of the obtained nucleotide sequences showed high similarity with $G$. intestinalis the TPI gene sequences were available in the NCBI database. The retrieved reference sequences together with the study sequences were subjected to multiple sequence alignment. Patterns of nucleotide variations were among the study sequences (Fig. 2), 20 (83.33\%) sequences showed high similarity with $G$. intestinalis assemblage B (from G1-20) \& 4 (16.66\%) sequences showed high similarity with assemblage A (from G21-24).

\section{Discussion}

In the present study, 33 out of $176(18.75 \%)$ examined fecal samples from symptomatic children were microscopically positive, but only 24 samples were positive using nPCR targeting TPI gene. Fahmy et al. (2015) reported that of 96 Giardia positive fecal specimens by microscopy, 77 samples were positive by nPCR. The negative results may be due to the presence of inhibitors in faecal samples, cyst quantity and quality, samples storage conditions, DNA extraction method, the gene targeted and the number of copies, and choice of primers and cycling conditions (Wilke and Robertson 2009).

The prevalence of giardiasis varied among children from different geographic locations between $1 \%$ and $36 \%$ and as high as $72 \%$ depending on the age group and country (Asher et al, 2014). In Egypt, there was a discrepancy in the prevalence rate of $G$. intestinalis, which varied between $7.9 \%$ (elBeshbishi et al, 2005) and 35\% (Fahmy et al, 2015). El Shazly et al. (2006) reported $19.6 \%$ among inpatients in Mansoura University Pediatric Hospital and Ismail et al. (2016) in Cairo reported prevalence of giardiasis in cohort of Egyptian children.

In the present study, $G$. intestinalis prevalence among the children based on micro- 
scopic examination was higher in summer (25\%) than spring (20\%) and autumn $(15.15 \%)$, and zero in winter. In contrast, molecular prevalence using nPCR was higher in the spring (28\%) than in autumn $(15.15 \%)$ and lastly summer $(6.9 \%)$. Using nPCR, there was significant association between the season in which the sample was positive and the status of Giardia infection $(\mathrm{P}=0.006)$. Eraky et al. (2014) in Benha reported that the high risk of acquiring parasitic infection was in summer due to the consumption of raw vegetables. Ismail et al. (2016) reported that $G$. intestinalis was detected throughout the year with a seasonal peak in mid-summer and late winter. Pasley et al. (1989) in Arkansas, USA, reported that higher Giardia prevalence was in summer related to the corresponding increase in outdoor activity, water source usage and drinking of untreated surface water. GonzálezMoreno et al. (2011) in Catalonia, Spain, reported no seasonality related to $G$. intestinalis prevalence

In the current study, the giardiasis prevalence by microscopy and nPCR was more in males than in females, but without significant difference. These results agreed with others (Abbass et al, 2011; Ismail et al, 2016; Hussein et al, 2017), probably due to the higher activity of male children especially outdoor in contaminated environment. But, Al-Mekhlafi et al. (2010) in Ismailia reported that the predominance of Giardia was higher in females than males, while Helmy et al. (2014) stated that sexes did not correlate with giardiasis in Ismailia Governorate.

The occurrence and prevalence of giardiasis varies according to the age of patients (Abbass et al, 2011; Ismail et al, 2016). In the present study, children from 3 to 8 years showed highest infection rate $(20.68 \%)$, followed by those from 9-12 years $(17.18 \%)$ and the lowest was in infant from one month to 2 years $(16 \%)$. This might be due to the outdoor activity of children from 3 to 8 years with lack the personal hygiene. This evidence was reported in young child ren (Abbass et al, 2011; Ismail et al, 2016).

$G$. intestinalis has two major genotypes, assemblage A and B the most common types of human giardiasis. Assemblage A can be further classified into sub-assemblage AI, which is found in humans and also in many animals; sub-assemblage AII were in humans, as well as in a few studies; and subassemblage AIII is found exclusively in animals (Cacciò et al, 2008; Heyworth 2016). Assemblage B subgroups are unresolved, and numerous assemblage $B$ variants contributed to human and animal infections (Feng and Xiao 2011; Ryan and Cacciò 2013). Anthroponotic infections were more frequent with assemblage $\mathrm{B}$ compared to A (Bahrami et al, 2017).

In the present study, two genetically distinct assemblages A and B of Giardia infections were recorded, assemblage B was predominant $(83.33 \%)$ in comparison with assemblage A (16.66\%). Similar assemblage distributions were reported in India (Traub et al, 2004), Egypt (Foronda et al, 2008), and Kuala Lumpur (Mahdy et al, 2009). But, this differed from that in Saudi Arabia, Yemen, Iran and Ethiopia where assemblage A was higher than assemblage B (Gelanew et al, 2007; Al-Mohammed 2011; Sarkari et al, 2012; Alyousefi et al, 2013). Others found that both assemblage A and assemblage B were present approximately with equal distribution (Roointan et al, 2013; Choy et al, 2014; Bahrami et al, 2017).

Assemblage A was more zoonotic transmission, with a wide range of animals acting as reservoir hosts. Although assemblage B was most likely transmitted from man to man, and also detected in animals, representing a zoonotic potential as well (Feng and Xiao 2011; Lebbad et al, 2011).

In the present study, though assemblage B was predominant among symptomatic persons, without association between giardiasis and any risk factors. This agreed with many studies (Molina et al, 2011; Alyousefi et al, 2013; Choy et al, 2014; Puebla et al, 2014; 
Fahmy et al, 2015).

Some studies reported a relation between G. intestinalis assemblages and clinical pictures, especially in children (Helmy et al, 2014; Hussein et al, 2017). El-Badry et al. (2017) and Hussein et al. (2017) reported a clear predominance of assemblage B among symptomatic children. Haque et al. (2005) in Bangladesh reported association between $G$. intestinalis assemblage $\mathrm{B}$ and asymptomatic infection. But, others reported a significant correlation between symptoms and assemblage A (Read et al, 2004; Sahagún et al, 2008; Sadek et al, 2013; Fouad et al, 2014). Nevertheless, many studies found no correlation between assemblages and symptoms (Choy et al, 2014; Bahrami et al, 2017). However, the relation between giardiasis assemblages and clinical manifestations remained unclear (Rafiei et al, 2013).

\section{Conclusion}

In this study, molecular analysis revealed that assemblages $\mathrm{A}$ and $\mathrm{B}$ are the most common types of Giardia infection among Egyptian children, with a predominance of assemblage B. These data suggested that anthroponotic transmission could be a domin ant transmission route for the giardiasis in Egypt.

Conflict of interest: The authors declared that they neither have conflict of interest nor received fund.

\section{References}

Abbass, NF, El-Shaikh, KA, Almohammady, MS, 2011: Prevalence of Giardia lamblia in diarrheic children in Almadinah Almunawarh, KSA. J. Taibah Univ. Sci. (JTUSCI ) 5:25-30.

Adam, EA, Yoder, JS, Gould, LH, Hlavsa, MC, Gargano, JW, 2016: Giardiasis outbreaks in the United States, 1971-2011. Epidemiol. Infect. 144: 2790-801.

Al-Mekhlafi, HM, Surin, J, Sallam, AA, Abdullah, AW, Mahdy, MA, 2010: Giardiasis and poor A vitamin status among aboriginal school children in rural Malaysia. Am. J. Trop. Med. Hyg. 83:523-7.

Al-Mohammed, HI, 2011: Genotypes of Giardia intestinalis clinical isolates of gastrointesti- nal symptomatic and asymptomatic Saudi children. Parasitol. Res. 108:1375-81.

Al-Yousefi, NA, Mahdy, MA, Xiao, L, Mahmud, R, Lim, YA, 2013: Molecular characterization of Giardia duodenalis in Yemen. Exp. Parasitol. 134, 2:141-7

Asher, AJ, Holt, DC, Andrews, RM, Power, ML, 2014: Distribution of Giardia duodenalis assemblages A and B among children living in a remote indigenous community of the Northern Territory, Australia. PLOS One 9, 11:e112058.

Bahrami, F, Zamini, GH, Haghighi, A, Khademerfan, MB, 2017: Detection and molecular identification of human Giardia isolates in the West of Iran. Biomed. Res. 28, 13:5687-92

Bayoumy, AM, Mohammed, KA, Shahat, SA, Ghannam, MM, Gazy Mel, S, 2010: Role of parasites among chronic diarrheic patients. J. Egypt Soc. Parasitol. 40:679-98.

Cacciò, SM, Beck, R, Lalle, M, Marinculic, A, Pozio, E, 2008: Multilocus genotyping of Giardia duodenalis reveals striking differences between assemblages A and B. Int. J. Parasito. 38, 13:1523-31.

Cacciò, SM, Ryan, U, 2008: Molecular epidemiology of giardiasis. Mol. Biochem. Parasitol. 160:75-80.

Choy, SH, Al-Mekhlafi, HM, Mahdy, MA, Nasr, NN, Sulaiman, M, et al, 2014: Prevalence and associated risk factors of Giardia infection among indigenous communities in rural Malaysia. Sci. Rep. 4:6909-16.

El-Badry, AA, Mohammed, FE, Abdel-Gwad, E, 2017: Predominance of Giardia intestinalis assemblage B in diarrhoeic children in Sharkia, Egypt. PUJ 10, 1:1-7

El-Beshbishi, SN, Abdel-Magied, AA, elNahas, HA, Azab, MS, el-Shazly AM, Morsy AT, et al, 2005: Geoparasites in rural Dakahlia Governorate, a preliminary based study for development of the community-based intervention programs. J. Egypt. Soc. Parasitol. 35, 3:105170.

El Shazly, AM, Awad, SE, Sultan, DM, Sadek, GS, Khalil, HH, Morsy, TA, 2006: Intestinal parasites in Dakahlia governorate, with different techniques in diagnosing protozoa. J. Egypt. Soc. Parasitol. 36, 3:1023-34.

Eraky, MA, Rashed, SM, Nasr, MS, ElHamshary, AM, Salah El-Ghannam, A, 2014: Parasitic contamination of commonly consumed 
fresh leafy vegetables in Benha, Egypt. J. Parasitol. Res. 2014: 613960. doi: 10.1155/ 2014/ 613960.

Fahmy, HM, El-Serougi, AO, El Deeb, HK, Hussein, HM, Abou-Seri, HM, et al, 2015: Giardia duodenal assemblages in Egyptian children with diarrhea. Eur. J. Clin. Microbiol. Infect. Dis. 34, 8:1573-81.

Feng, Y, Xiao, L, 2011: Zoonotic potential and molecular epidemiology of Giardia species and giardiasis. Clin. Microbiol. Rev. 24:110-40.

Foronda, P, Bargues, MD, Abreu-Acosta, N, Periago, MV, Valero, MA, 2008: Identification of genotypes of Giardia intestinalis of human isolates in Egypt. Parasitol. Res. 103:1177-81.

Fouad, SA, Esmat, S, Basyoni, MM, Farhan, MS, Kobaisi, MH, 2014: Molecular identification of Giardia intestinalis in patients with dyspepsia. Digest. 90, 1:63-71.

Gelanew, T, Lalle, M, Hailu A, Pozio, E, Cacciò, SM, 2007: Molecular characterization of human isolates of Giardia duodenalis from Ethiopia. Acta Trop. 102:92-9.

González-Moreno, O, Domingo, L, Teixidor, J, Gracenea, M, 2011: Prevalence and associated factors of intestinal parasitisation: a crosssectional study among outpatients with gastrointestinal symptoms in Catalonia, Spain. Parasitol. Res. 108:87-93.

Haque, R, Roy, S, Kabir, M, Stroup, SE, Mondal, D, et al, 2005: Giardia assemblage a infection and diarrhea in Bangladesh. J. Infect. Dis. 192, 12:2171-3.

Helmy, YA, Klotz, C, Wilking, H, Krucken, J, Nockler, K, et al, 2014: Epidemiology of Giardia duodenalis infection in ruminant livestock and children in the Ismailia province of Egypt: insights by genetic characterization. Parasit. Vectors; 7:321.

Heyworth, M, 2016: Giardia duodenalis genetic assemblage and host. Parasite. 23:13.

Hussein, EM, Ismail, OA, Mokhtar, AB, Mohamed, SE, Saad, RM, 2017: Nested PCR targeting intergenic spacer (IGS) in genotyping of Giardia duodenalis isolated from symptomatic and asymp-tomatic infected Egyptian school children. Parasitol. Res. 116: 763-71.

Ismail, MAM, El-Akkad, DMH, Rizk, EMA, El-Askary, HM, El-Badry, AA, 2016: Molecular seasonality of Giardia lamblia in a cohort of Egyptian children: A circannual pattern. Parasitol. Res. 115, 11:4221-7.

Lai, A, Hales, S, French, N, Baker, MG, 2012:
Seasonality in human zoonotic enteric diseases: a systematic review. PLoS One. 7, 4:e31883.

Lasek-Nesselquist, E, Welch, DM, Sogin, ML, 2010: The identification of a new Giardia duodenalis assemblage in marine vertebrates and a preliminary analysis of G. duodenalis population biology in marine system. Int. J. Parasitol. 40:1063-74.

Lebbad, M, Petersson, I, Karlsson, L, BoteroKleiven, S, Andersson, O, et al, 2011: Multilocus Genotyping of Human Giardia Isolates Suggests Limited Zoonotic Transmission and Association between Assemblage B and Flatulence in Children. PLOS Negl. Trop. Dis. 71:103.

Mahdy, AM, Surin, J, Wan, KL, Mohd-And an, A, Al-Mekhlafi, MH, et al, 2009: Giardia intestinalis genotypes: Risk factors and correlation with clinical symptoms. Acta Trop. 112:6770.

Molina, N, Pezzani, B, Ciarmela, M, Orden, A, Rosa, D, et al, 2011: Intestinal parasites and genotypes of Giardia intestinalis in school children from Berisso, Argentina. J. Infect. Dev. Ctries. 5, 7:527-34.

Pasley, JN, Daly, JJ, McCullough, D, Mc Chesney, T, Daly, EB, et al, 1989: Circannual incidence of Giardia lamblia. Chronobiol. Int. 6, 2:185-9.

Rafiei, A, Roointan, SE, Samarbafzadeh, RA, Shayesteh, AA, Shamsizadeh, A, et al, 2013: Investigation of possible correlation between $\mathrm{Gi}^{-}$ ardia duodenalis genotypes and clinical symptoms in southwest of Iran. Iran. J. Parasitol. 8, 3: 389-95.

Read, CM, Monis, PT, Thompson, RC, 2004: Discrimination of all genotypes of Giardia duodenalis at the glutamate dehydrogenase locus using PCR-RFLP. Infect. Genet. Evol. 4:125-30.

Robertson, LJ, Hanevik, K, Escobedo, AA, Morch, K, Langeland, N, 2010: Giardiasiswhy do the symptoms sometimes never stop? Trends Parasitol. 26:75-82.

Roointan, ES, Rafiei, A, Samarbaf-Zadeh, A R, Shayesteh, A, Shamsizadeh, A, et al, 2013: Genotype analysis of Giardia lamblia isolated from children in ahvaz, southwest of Iran. Jundishapur. J. Microbiol. 6:279-83.

Ryan, U, Cacciò, SM, 2013: Zoonotic potential of Giardia. Int. J. Parasitol. 43, 12/13:943-56.

Sadek, GS, El-Settawy, MA, Soha, A, Nasr, S A, 2013: Genotypic characterization of Giardia duodenalis in children in Menoufia and Sharkia 
Governorates. Egypt Life Sci. J. 10, 1:4006-15.

Sahagún, J, Clavel, A, Goñi, P, Seral, C, Llorente, MT, et al, 2008: Correlation between the presence of symptoms and the Giardia duodenalis genotype. Eur. J. Clin. Microbiol. Infect. Dis. 27:81-3.

Sarkari, B, Ashrafmansori, A, Hatam, GR, Motazedian, MH, Asgari, Q, 2012: Genotyping of Giardia lamblia isolates from human in southern Iran. Trop. Biomed. 29:366-71.

Savioli, L, Smith, H, Thompson, A, 2006: Giardia and cryptosporidium join the neglected diseases initiative. Trends Parasitol. 22, 5:203-8.

Sulaiman, IM, Fayer, R, Bern, C, Gilman, RH, Trout, JM, et al, 2003: Triosephosphate isomerase gene characterization and potential zoonotic transmission of Giardia duodenalis.
Emerg. Infect. Dis. 9: 1444-52.

Traub, R, Monis, P, Robertson, I, Irwin, P, Mencke, N, et al, 2004: Epidemiological and molecular evidence supports the zoonotic transmission of Giardia among humans and dogs living in the same community. Parasitology 128:253-62.

Wilke, H, Robertson, LJ, 2009: Preservation of Giardia cysts in stool samples for subsequent PCR analysis. J. Microbiol. Meth. 78, 3:292-6.

WHO, 2015: World Health Statistics. Geneva Switzerland. http://apps.who.int/iris/bitstream/ 10665/170250/1/9789240694439_eng.pdf.

Younas, M, Shah, S, Talaat, A, 2008: Frequency of Giardia intestinalis infection in children with recurrent abdominal pain. J. Pak. Med. Assoc. 58:171-4.

\section{Explanation of figures}

Fig. 1: Agarose gel electrophoresis for products of nPCR targeting TPI gene of G. intestinalis at 530 bp .Lane 1 to 7 : Positive samples. Lane 8: Negative control. Lane 9: Positive control. Lane 10: 100 bp DNA molecular weight marker "ladder".

Fig. 2: Multiple sequence alignment of sequenced DNA and reference G. intestinalis sequences on NCBI-BLAST, with 514 nucleotide positions in this matrix data. Similarity regions between sequences shown as dots, while dispersed letters indicate nucleotide variations. Gaps represented in dashes, showed 2 patterns of nucleotide diversity, assemblage B pattern (G1-G20) and assemblage A pattern (G21-G24).

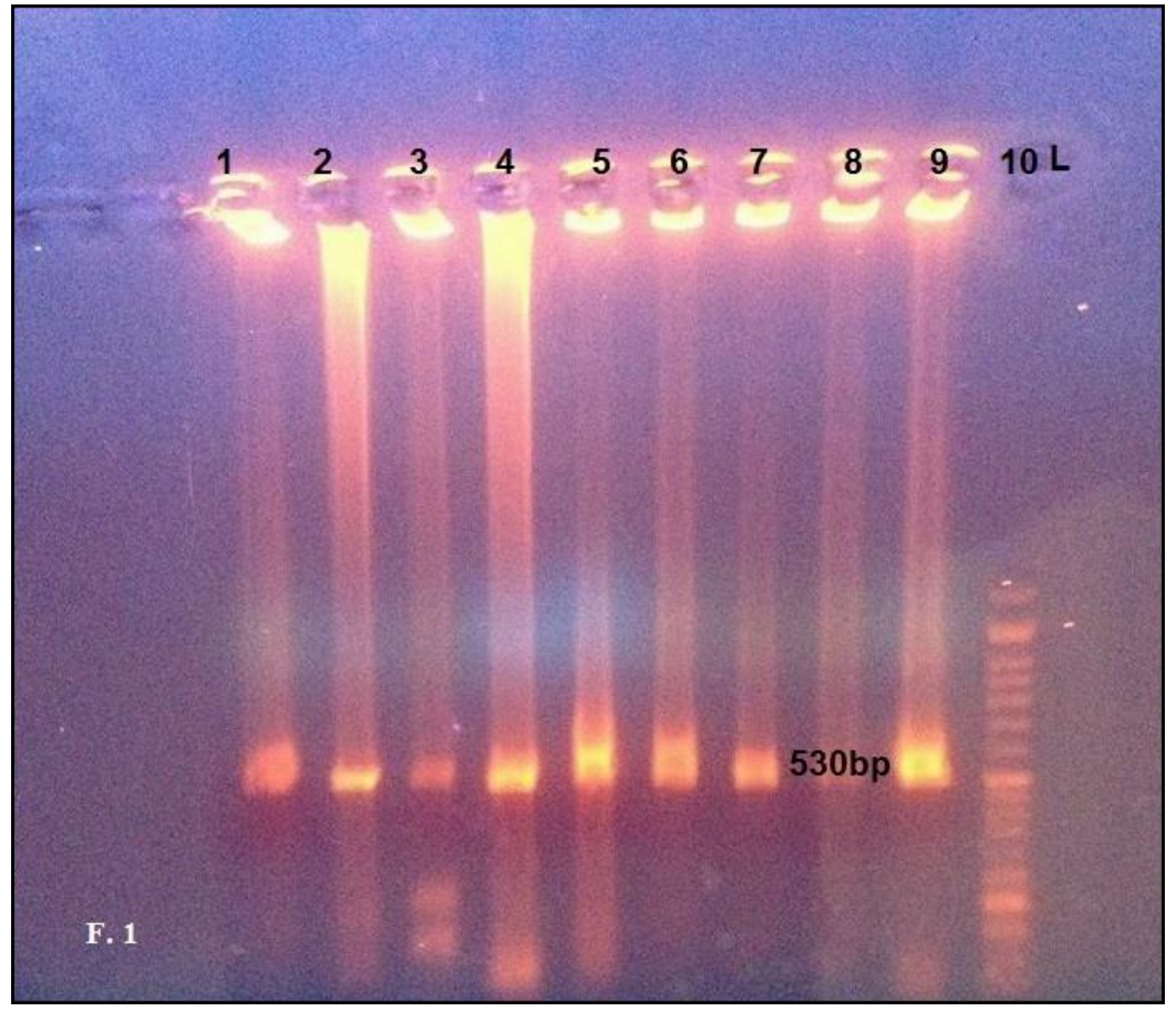




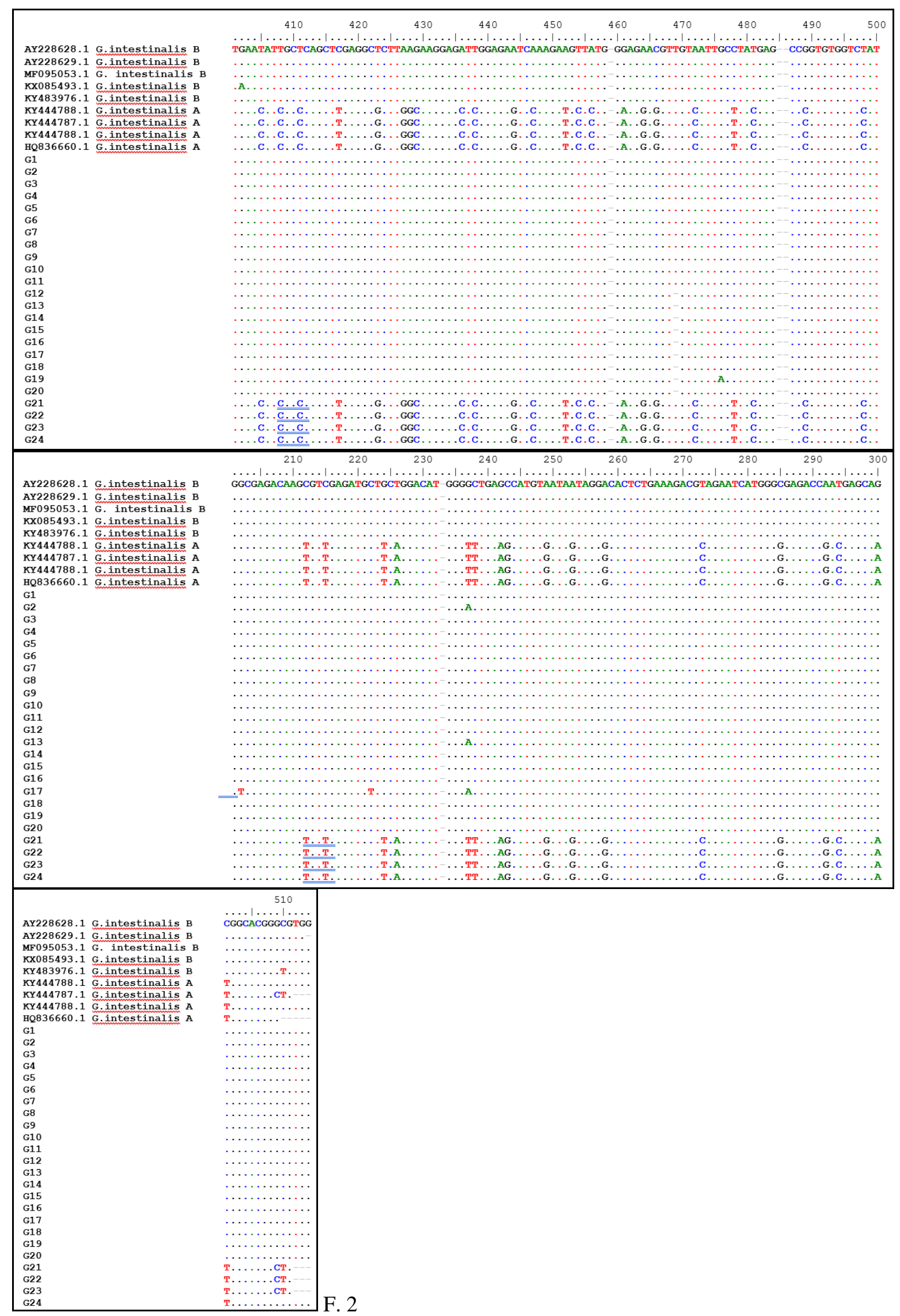

